\title{
AUTORIZACIONES JUDICIALES PREVIAS: ESCUDO PROTECTOR DE LOS DERECHOS CONSTITUCIONALMENTE ASEGURADOS
}

\author{
María Francisca Zapata G. \\ Juez de Garantía de Vicuña \\ Profesora de Derecho Procesal Penal \\ Universidad Católica del Norte (Sede Coquimbo)
}

1. Ubicación contextual y conceptual de la institución de las autorizaciones judiciales previas. 2. Ubicación de las autorizaciones judiciales previas en el sistema de garantías. 3. Impacto del artículo $80 \mathrm{~A}$ de la Constitución Política de la República y artículo 9 del Código Procesal Penal sobre el nuevo proceso: un paso más en su constitucionalización. 4. Forma de expedición de las autorizaciones judiciales previas: ¿verbalidad o escrituración? 5. Diferencia conceptual entre autorización judicial previa y orden judicial. 6. Oportunidad para solicitar autorización judicial y juez competente para pronunciarse. 7. Uso de la fuerza para llevar a cabo la diligencia autorizada judicialmente. 8. Consecuencias derivadas de la realización de una diligencia intrusiva sin autorización judicial previa.-

1.- Ubicación contextual y conceptual de la institución de las autorizaciones judiciales previas.

Sabemos que de acuerdo a la Constitución Política de la República, Ley Orgánica Constitucional del Ministerio Público y Código Procesal Penal, el Ministerio Público dirigirá en forma exclusiva la investigación de los hechos constitutivos de delito, los que determinen la participación punible y los que acrediten la inocencia del imputado. Para ello, el Ministerio Público podrá impartir órdenes directas a las Fuerzas de Orden y Seguridad durante la investigación.

Específicamente el artículo $77 \mathrm{CPP}^{1}$ señala que los fiscales ejercerán y sustentarán la acción penal pública y con ese propósito practicarán todas las diligencias que fueren conducentes al éxito de la investigación y dirigirán la actuación de la policía, con estricta sujeción al principio de objetividad, consagrado en la Ley Orgánica Constitucional del Ministerio Público.- Reafirma aún más esta idea el artículo 180 del

${ }^{1}$ CPP: Código Procesal Penal 
CPP, que señala que los fiscales dirigirán la investigación y podrán realizar por sí mismos o encomendar a la policía todas las diligencias de investigación que consideren conducentes al esclarecimiento de los hechos.

La policía por su parte, será auxiliar del ministerio público en las tareas de investigación y deberá llevar a cabo las diligencias necesarias de conformidad a las instrucciones que le dirigieren los fiscales. Los funcionarios de la policía deberán cumplir de inmediato y sin más trá mite las órdenes que les impartieren los fiscales, cuya procedencia, conveniencia y oportunidad no podrán calificar.

Según se concluye inequívocamente de lo que se ha expuesto, la regla general en el nuevo proceso es que la policía ejecute sus tareas bajo la dirección y responsabilidad de los fiscales y de acuerdo a las instrucciones que éstos les impartan para los efectos de la investigación, sin perjuicio de lo cual, corresponde a estos funcionarios realizar una serie de actuaciones, sin necesidad de recibir previamente instrucciones particulares de los fiscales, a las que se refiere explícitamente el artículo 83 del CPP: prestar auxilio a la víctima, practicar la detención en los casos de flagrancia, resguardar el sitio de suceso, identificar testigos y consignar sus declaraciones, recibir las denuncias del público y efectuar las demás actuaciones que disponga la ley.

Hasta aquí podemos sostener que el Ministerio Público y la policía no sólo pueden, sino que deben llevar a cabo todas aquellas diligencias conducentes al esclarecimiento de los hechos. observamos una cierta libertad en la iniciativa y desenvolvimiento de esta labor, pero cabe preguntarse ¿ esta libertad es absoluta?

La respuesta es definitivamente negativa. La facultad para realizar diligencias de investigación que posee el Ministerio Público tiene una barrera que, si bien no es infranqueable, es de todas formas insoslayable, y está constituida por el régimen de las autorizaciones judiciales previas, estatuido en los artículos $80 \mathrm{~A}$ de la Constitución Política de la República; 4 de la Ley Orgánica Constitucional del Ministerio Público y 9 del Código Procesal Penal, con relación a aquellas diligencias que perturban, restringen o privan a una persona del ejercicio de los derechos que la constitución asegura.

En consecuencia -y lo explicita el propio artículo 9 CPP- cuando una diligencia de investigación pudiere producir alguno de tales efectos, el fiscal deberá solicitar previamente autorización al juez de garantía.

En otras palabras, el fiscal del MP encargado de la investigación en un caso concreto podrá llevar a cabo libremente todas las diligencias y actuaciones que estime pertinentes para esclarecer el hecho punible y sus responsables, de las cuales recabará la prueba que incorporará posteriormente al juicio oral. Sin embargo, si con la práctica de alguna diligencia se fuere a privar, restringir o perturbar siquiera el ejercicio de un 
derecho que la Constitución asegura, el fiscal deberá previamente a su realización, solicitar y obtener autorización judicial.

Como señala Binder: "El Ministerio Público, con sus inmensas atribuciones de investigación y de dirección de la policía no puede tener un poder omnímodo ni los ciudadanos pueden quedar indefensos ante él".

"Es allí donde aparece el juez de garantías, durante la investigación. Cada vez que ésta roce algún derecho constitucional o una de las libertades cívicas será necesaria la autorización del juez".

"Ese juego dialéctico entre el fiscal, que es en cierto modo el promotor del ejercicio del poder penal y el que lo lleva adelante, y el juez, que representa el propósito de poner freno a una eventual arbitrariedad de ese poder, constituye un sistema por el cual se garantiza que esa síntesis, que se da en todo proceso, no se resuelva en contra de los derechos fundamentales de las personas",

Por su parte, en el Mensaje del Código Procesal Penal, S.E. el Presidente de la República consigna: "En el diseño planteado por el proyecto, las amplias facultades del ministerio público durante la instrucción tienen como límite los derechos individuales de las personas. En los casos en que su actividad afecte o pueda afectar esos derechos, procederá siempre la intervención judicial, en general previa, por medio de audiencias orales, en las que el juez deberá calificar la legalidad de la actuación y cautelar por el respeto a los derechos de quienes puedan resultar afectados por ella. Entre las medidas que requieren esta intervención judicial estarán siempre las medidas cautelares dirigidas en contra del imputado y también algunas actividades de investigación que puedan afectar sus derechos o los de cualquier otra persona. Al efecto, el proyecto enumera un conjunto de medidas específicas que requieren este control, pero a la vez consagra la posibilidad de que el afectado requiera al juez reclamando de cualquier otra actividad persecutoria que pueda implicar afectación de sus derechos. ${ }^{3}$

Como vemos, esta barrera según hemos dicho aparece insoslayable, pues siempre y en todo caso, el fiscal deberá pedir autorización judicial para practicar una diligencia que afecta el ejercicio de los derechos constitucionalmente asegurados. Sin embargo, tal barrera no es infranqueable, pues otorgada la autorización, puede el órgano persecutor perturbar, restringir e incluso privar del ejercicio de alguno de estos derechos al imputado o terceros precisamente con la realización de esta diligencia.

2 BINDER, Alberto, "Principios fundamentales del proceso penal acusatorio Ideas y Materiales para la reforma a la fusticio Penal". Buenos Aires p 99.

${ }^{3}$ Mensaje de S.E el Presidente de la República al Proyecto de Ley que establece un nuevo Código Procesal Penal. 
La gama de los derechos constitucionalmente asegurados cuyo ejercicio se pretende resguardar con la exigencia de autorización judicial previa es amplia. Para conocer su extensión basta con recurrir al Capítulo III de la Constitución Política de la República: "De los Derechos y Deberes Constitucionales", y seleccionar los pertinentes, es decir, aquellos derechos cuyo ejercicio pudiera verse perturbado, privado o restringido por la práctica de diligencias de investigación del ministerio público o su auxiliar, la policía. Claramente aparecen de inmediato el derecho a la vida, integridad física y síquica de la persona, el respeto y protección a la vida privada y pública y a la honra de la persona y su familia, la inviolabilidad del hogar y de toda forma de comunicación privada, entre otros.

Es preciso insistir en un punto antes de proseguir. La exigencia de autorización judicial previa, es para contar con un estudio de procedencia y pertinencia efectuado por un órgano jurisdiccional respecto de la diligencia de carácter intrusivo, entendiendo por tal aquélla que lleva implícita la posibilidad de afectar el ejercicio de derechos constitucionalmente asegurados. Es un control judicial en el que se ponderará la necesidad de la diligencia en relación con el derecho cuyo ejercicio se verá amagado con su realización.

No está de más señalar, a la luz de ciertos debates que se han originado entre los operadores del sistema, que lo que se pretende proteger es el ejercicio de ciertos derechos que la Constitución Política asegura.

De este modo, si un fiscal tiene la duda en orden a la necesidad de obtener autorización judicial para realizar una diligencia o actuación tendrá que dilucidar si con su práctica se afecta alguno de los derechos que la Constitución asegura a todas las personas. Para ello deberá recurrir materialmente a la Constitución y revisar su catálogo de derechos.

La misma tarea deberá llevar a cabo el juez de garantía, en el caso que se produzca un debate acerca de la licitud de la prueba que se ha obtenido en una diligencia que se ha llevado a cabo sin autorización judicial en la creencia, por parte del fiscal, que no era necesaria, efectuando evidentemente un ejercicio intelectual exigente, que se ponga encarecidamente en la situación práctica en orden a establecer si hubo o no privación, restricción o perturbación del ejercicio del derecho en cuestión.

Lo anterior nos permite afirmar que no cualquier afectación de derechos exige autorización judicial previa a la diligencia en cuestión, sino que es una exigencia que se justifica en cuanto se trate del ejercicio de derechos constitucionalmente asegurados. Así, se descarta este control jurisdiccional previo en el caso que se trate de otros derechos que carecen de rango constitucional. 
Refuerza esta idea, más allá de la literalidad del artículo $80 \mathrm{~A}$ inciso tercero de la Constitución Política y del propio artículo 9 del CPP la norma que sigue a este último: artículo 10 "Cautela de garantías." Éste señala que en cualquier etapa del procedimiento en que el juez de garantía estimare que el imputado no está en condiciones de ejercer los derechos que le otorgan las garantías judiciales consagradas en la Constitución Política, en las leyes o en los tratados internacionales ratificados por Chile y que se encuentran vigentes, adoptará, de oficio o a petición de parte, las medidas necesarias para permitir dicho ejercicio.

Evidentemente el ámbito del artículo 10 es diverso al del artículo 9, pero nos sirve para acotar sus diferentes objetos de protección: por una parte el artículo 9 del CPP extiende su alcance al ejercicio de todos los derechos que la Constitución asegura al imputado o a terceros, mientras que el artículo 10 sólo protege los derechos del imputado otorgados por las garantías judiciales.

Por otra parte, el artículo 9 del CPP cubre los derechos en tanto están constitucionalmente asegurados y en cambio el artículo 10 cautela el ejercicio de los derechos que le otorgan las garantías judiciales, ya sea que se encuentren consagradas en la Constitución, en las leyes o en los tratados internacionales ratificados por Chile.

\section{2.- Ubicación de la autorizaciones judiciales previas en el sistema de garantías}

Los pilares conceptuales del sistema de garantías están constituidos, según expresa Binder por una teoría del delito "que pretende establecer los requisitos verificables del acto punible"; una teoría del juicio, "cuya función es explicar el funcionamiento de las garantías y favorecer su desarrollo" y la teoría de la prueba, que "regula el ingreso y utilización de la información" ${ }^{4}$ En este tema, lo que nos interesa es precisamente este último pilar.

Cuando un juez toma una decisión definitiva en el proceso, condenando o absolviendo a un imputado, lo hace sobre la base de la información que las partes han ingresado al juicio. Sabemos que el juez nunca ha podido tomar conocimiento en forma personal ni directa de estos hechos sucedidos en un momento pasado y que configuran el conflicto, sin embargo su deber es reconstruirlos o redefinirlos en forma definitiva, en un cabal esfuerzo por aproximarse a la verdad. Una vez que alcance el grado de certeza - incerteza para decidir, pondrá en conocimiento de la comunidad aquella verdad que pasará a ser inamovible. Sostiene Ferrajoli: "La función judicial, y particularmente la penal, difiere de todas las demás funciones del estado porque es una actividad cognoscitiva, donde las elecciones y las decisiones vienen justificadas por criterios

${ }^{4}$ BINDER, Alberto: El Incumplimiento de las Formas Procesales. Ad-Hoc, Buenos Aires, p. 71. 
pragmáticos y subjetivos pero siempre referidos, como en cualquier otra forma de conocimiento, a la búsqueda de la verdad objetiva. Es claro que, a diferencia del conocimiento científico, las decisiones sobre la verdad que intervienen en el juicio penal expresan un poder, dado que forman el presupuesto del silogismo práctico que concluye con un fallo, sea de absolución o de condena. Se trata sin embargo de un poder "de comprobación" o de "verificación" distinto de cualquier otro poder público y típicamente propio de la función judicial".

En esta búsqueda de la verdad el juez se va a encontrar con una serie de límites, básicamente constituidos por el reconocimiento de los atributos de la persona humana, pues, según hemos dicho, esta verdad pasará a instalarse en la sociedad en forma definitiva. Esta idea está en Binder al decir que "el juez le asigna valor de verdad a un relato final por un acto de poder y nada podría cambiar esta circunstancia. Por esta razón los sistemas procesales han construido reglas de prueba: para que ese acto de poder del juez, que consiste en un imperium de gran fuerza (porque asignará valor de verdad a un conjunto de afirmaciones) tenga el menor margen posible para la arbitrariedad y el azar."

La verdad, según el rol asignado en el sistema inquisitivo, era central en el proceso, su meta. La verdad legitimaba la decisión, sin embargo, en los sistemas acusatorios la verdad cumple principalmente una función de garantía al dibujarse como un límite al poder penal del estado. Esto repercute en el sistema probatorio, donde las reglas de prueba pasan a ser normas de garantía pues son límites a la búsqueda de esa verdad.

Dentro de la Teoría de la Prueba, Binder destaca tres niveles de características diversas con relación a la posibilidad de acceso a la información y que denotan que "los límites será más estrictos en tanto la actividad de adquisición de información se vaya acercando al imputado mismo o a sus lugares de vida íntima" . Exponiendo esta idea sostiene: "De este modo el principio básico es que el Estado y el proceso penal se hallan limitados en sus posibilidades de adquirir información, ya que un número de garantías procesales (reconocidas en la mayoría de las leyes fundamentales y en los pactos internacionales sobre Derechos Humanos) conforman un escudo protector, que busca impedir que la actividad de investigación avasalle la dignidad humana.,"

\footnotetext{
${ }^{5}$ FERRAJOLI, Luigi. Derecho y Razón. Teoría del Garantism. Buenos Aires, p. 69.

${ }^{6}$ BINDER, Alberto, Principios fundamentales del proceso penal acusatorio Ideas y Materiales para la reforma a la fusticio Penal, Buenos Aires, p. 78 y 79.

'BINDER. El Incumplimiento de las formas procesales, Buenos Aires. p. 81

${ }^{8}$ BINDER. El relato del hecho y la regularidad del proceso. Justicia Penal y Estado de Derecho, Buenos Aires. p. 27
} 
El primer nivel es "absolutamente intangible" ${ }^{9}$ y está constituido por las normas que establecen el derecho a no declarar contra uno mismo y prohíben la tortura. El Estado no puede traspasar este nivel para adquirir información en caso alguno.

El segundo nivel "puede ser definido como la protección de las esferas primarias de actividad de las personas". "Este nivel permite la actuación estatal tras la información, pero a través de rigurosos procedimientos de control jurisdiccional, constituidos por las autorizaciones judiciales.

El tercer nivel dice relación con la determinación de los medios de prueba: "Los sistemas procesales han agrupado las normas limitadoras en grupos vinculados a formas de adquisición de esa información. Este agrupamiento obedece en conjunto a la idea de límite ya que la información ingresará por esas vías de acceso y no por otros. Es verdad que los sistemas procesales suelen tener una norma genérica que permite utilizar medios de prueba distintos de los previstos, pero los asimila a alguno de ellos y les extiende las formalidades del medio análogo. Esto significa que la información no puede ingresar al juicio por otras vías que las previstas legalmente.

Según hemos visto, hay un campo constituido por el ámbito privado del imputado, en que los órganos de persecución penal pueden ingresar y recopilar información, pero, consciente de que su recopilación puede afectar el desarrollo de su vida intima, el ordenamiento establece un sistema de protección constituido por las autorizaciones judiciales que deben otorgarse en forma previa a la práctica de la diligencia en particular. En otras palabras, la esfera primaria de actividad de las personas es afectable, pero respetando los procedimientos que se han establecido en protección de la misma.

En conclusión, las autorizaciones judiciales previas cumplen un papel de límite a la búsqueda de la verdad (información) que se presenta en forma insoslayable cada vez que esta verdad se pretenda buscar en los "ámbitos de actuación primaria" de las personas.

"BINDER, Alberto, Principios fundamentales del proceso penal acusatorio Ideas y Materiales para la reforma a la fusticio Penal. Buenos Aires, p. 27.

${ }^{10}$ BINDER, Alberto, Principios fundamentales del proceso penal acusatorio Ideas y Materiales para la reforma a la fusticio Penal. Buenos Aires, p. 28

${ }^{11}$ BINDER, Alberto, Principios fundamentales del proceso penal acusatorio Ideas y Materiales para la reforma a la fusticio Penal. Buenos Aires p 80. 


\section{3.- Impacto del artículo $80 \mathrm{~A}$ de la Constitución Política de la República y artículo 9 del} Código Procesal Penal, sobre el nuevo proceso: un paso más en su constitucionalización.

El Mensaje de S.E. el Presidente de la República al Código Procesal Penal, señala que la modernización del sector justicia ha sido definida como una política que tiende a adecuar el conjunto de las instituciones que participan de la administración de justicia a los procesos de desarrollo político y económico experimentado por nuestro país en las últimas décadas. Agrega que el cambio político más importante en Chile ha sido la consolidación del modelo democrático, el que a su vez exige el respeto a los derechos humanos como un principio fundamental de legitimidad. Este cambio político exige una justicia accesible, imparcial, igualitaria y que maximice las garantías.

En el objetivo global de modernización de la justicia, que define como la maximización de las garantías y la imparcialidad del estado democrático y el incremento del bienestar, se encuentran, entre otras áreas en que es necesario efectuar reformas, el área del sistema penal. Señala que la reforma al sistema penal constituye una labor que se extiende más allá de la reforma al proceso penal, pero que supone, sobre todo de un modo urgente y prioritario, modificar el proceso penal para transformarlo en un juicio genuino, con igualdad de armas entre el Estado y el inculpado y con plena vigencia de la oralidad, la oportunidad y la inmediación.

Según vemos entonces, se encuentra en la base de esta nueva construcción la aspiración de satisfacer las exigencias que hace a la justicia el respeto a los derechos humanos como un principio fundamental de legitimidad.

La exigencia de autorización judicial previa aparece como una institución de resguardo de los derechos que la Constitución asegura frente a la labor investigativa, pues los antecedentes surgidos en esa investigación sólo podrán convertirse en prueba durante el juicio en la medida que se han respetado estos derechos y sus normas protectoras.-

La gran importancia que se otorga a los derechos individuales en el nuevo código constituye una novedad y esta constatación permite afirmar que se ha producido un avance en la constitucionalización del proceso penal.

Desde sus orígenes esta norma establecida en el artículo 9 del CPP -que primeramente se contuvo en los artículos 96 y 282- y en la evolución que experimentó en el Parlamento se advierte esta tendencia.

Recordemos que el proyecto original estableció esta normativa en los siguientes términos: "Artículo 96: Facultades. En el ejercicio de sus funciones el ministerio público llevará adelante todas las actuaciones conducentes al éxito de la investigación. Sin 
perjuicio de ello cuando éstas afecten o puedan afectar derechos individuales, sólo podrá proceder autónomamente en los casos en que la ley lo autorice en forma expresa, debiendo en todos los demás requerir autorización judicial previa.

"Artículo 282: Autorización previa. Cuando la práctica de alguna de las diligencias de investigación del ministerio público pudiere significar la perturbación o vulneración de los derechos fundamentales del imputado o de alguna otra persona, deberá previamente solicitar autorización al juez de control de la instrucción.

El juez de control de la instrucción velará por el cumplimiento de los requisitos previstos en cada caso. La resolución que autorice la práctica de la diligencia será siempre fundada y deberá expresar los motivos que la justifican."

El artículo 96 original que se ha transcrito fue aprobado con modificaciones, "con el objeto de adecuar su contenido al artículo $80 \mathrm{~A}$ de la Constitución y reordenar las materias que consulta, con el propósito de dar mayor claridad a la norma" ${ }^{13}$.

De esta manera, la disposición fue redactada en esta etapa como sigue: "Artículo 96: Facultades. En el ejercicio de sus funciones, los fiscales del ministerio público llevarán adelante todas las actuaciones conducentes al éxito de la investigación.

No obstante, las actuaciones que priven al imputado o a terceros del ejercicio de los derechos que la Constitución asegura, o lo restrinjan o perturben, requerirán aprobación judicial previa." ${ }^{14}$

El artículo 282 original también sufrió una alteración, en su numeración y contenido en el mismo sentido, según se advierte de la siguiente transcripción: "Artículo 267: Autorización previa. Cuando alguna de las diligencias de investigación del fiscal del ministerio público pudieren privar al imputado o terceros del ejercicio de los derechos que la Constitución les asegura, o los restrinjan o perturben, deberá solicitar autorización del juez de control para practicarla.

El juez de control de la instrucción velará por el cumplimiento de los requisitos previstos en cada caso. La resolución que autorice la práctica de la diligencia será siempre fundada y deberá expresar los motivos que la justifiquen." ${ }^{15}$

\footnotetext{
${ }^{12}$ Cámara de Diputados, Comisión de Constitución, Legislación y Justicia, Historia de la Ley N 1: Nuevo Código Procesal Penal (Boletín N 1630-07) Primer Trámite Constitucional, Tomo I. Publicación Oficial. p. 127 y 161.

${ }^{3}$ Cámara de Diputados, Comisión de Constitución, Legislación y Justicia, Historia de la Ley N 1: Nuevo Código Procesal Penal (Boletín N 1630-07) Primer Trámite Constitucional, Tomo II. Publicación Oficial. p. 271.

${ }^{14}$ Cámara de Diputados, Comisión de Constitución, Legislación y Justicia, Historia de la Ley N 1: Nuevo Código Procesal Penal (Boletín N 1630-07) Primer Trámite Constitucional, Tomo I. Publicación Oficial. p. 390.
} 
Posteriormente en el Senado, el artículo 96 fue reformulado y refundido: "La Comisión fue de parecer que, si bien la repetición de la norma del artículo $80 \mathrm{~A}$ de la Carta Fundamental que hacen los artículos 93 y 96 se pudo justificar por afanes didácticos en su momento, ha perdido razón de ser luego de la aprobación de la Ley Orgánica Constitucional del Ministerio Público.

Por lo mismo, estimó conveniente replantearlos, a la luz de las funciones básicas del Ministerio Público: por una parte, ejercer y sustentar la acción penal pública en conformidad a la ley, en segundo lugar, practicar todas las diligencias conducentes al éxito de la investigación, y finalmente, dirigir la actuación de la policía.

Al mismo tiempo, estuvo conteste en refundir ambos artículos con el 94, que consagra el principio de objetividad, el cual ha sido instituido en el artículo $3^{\circ}$ de la Ley Orgánica Constitucional del Ministerio Público, por lo que no se justifica su repetición, sino que solamente una alusión al mismo."

Finalmente el artículo 267 que veníamos aludiendo se transforma en al artículo 9 y nos acompaña hasta hoy, en los mismos términos.-

De esta evolución podemos advertir que hay un fortalecimiento de la institución, lo que se evidencia por los términos con que se fijó su contenido y por la ubicación que en definitiva se le dio entre los principios básicos señalados en el Libro Primero, junto a otros de tradicional envergadura, como el principio de juicio previo, juez natural, y presunción de inocencia.

De esta manera, podemos sostener que con el nuevo entramado consistente en introducir expresamente en la normativa del Código Procesal Penal ciertos principios que tradicionalmente han contado con raigambre constitucional y establecer el ré gimen de las autorizaciones judiciales previas, que abre un abanico protector hacia los derechos individuales, se ha fortalecido y profundizado la tendencia hacia la constitucionalización del proceso penal.

Acerca de este tema, nos dice Binder: "En un estado de derecho el juzgamiento de una persona, a resultas del cual puede perder su libertad, a veces por el resto de su vida, está regulada por un conjunto de principios conformados históricamente y que tiene la finalidad de proteger a los ciudadanos de las arbitrariedades cometidas a lo largo de la historia por ese poder de encarcelar a los conciudadanos que se le reconoce al estado, por lo menos por ahora. A partir del proceso de constitucionalización que se

\footnotetext{
${ }^{15}$ Cámara de Diputados, Comisión de Constitución, Legislación y Justicia, Historia de la Ley N 1: Nuevo Código Procesal Penal (Boletín N¹630-07) Primer Trámite Constitucional, Tomo I. Publicación Oficial. p. 422.

${ }^{16}$ Senado de la República Comisión de Constitución, legislación, justicia y Reglamento, Historia de la Ley Nuevo Código Procesal Penal (Boletín N 1630-07). Segundo Trámite Constitucional, p.130.
} 
desarrolla a partir del siglo XIX, esos principios se consideran como el núcleo central de un estado de derecho y por ello han sido consagrados en todos los pactos internacionales de derechos humanos.,"

\section{4.-Forma de expedición de las autorizaciones judiciales previas: ¿verbalidad o escrituración?}

Entre los principios formativos del nuevo procedimiento penal se encuentra el de la oralidad, que rige el juicio oral en términos omnipresentes y constituye, aunque en términos no absolutos, uno de los "principio-pilares" sustentadores de su construcción preliminar, es decir, del amplio espectro que le corresponde conocer al Juez de Garantía.

En esta primera etapa que concluye con el cierre de la investigación está presente, como en todo proceso, la tensión entre la eficacia de la persecución penal y el respeto a las garantías constitucionales.

Binder expresa que "para una correcta comprensión del derecho procesal penal se debe tener en cuenta que en la base de su formación básica tiene lugar un conflicto entre dos tendencias que normalmente han sido presentadas como antagónicas y cuya síntesis se ha mostrado como un ideal. Sin embargo, en realidad, una y otra se hayan siempre presentes en el proceso penal." $\mathrm{Y}$ agrega: "La primera de estas fuerzas o tendencias es la que se preocupa por establecer un sistema de garantías o resguardos frente al uso de la fuerza estatal. Se procura en este caso evitar que el uso de la fuerza se convierta en un hecho arbitrario. Su objetivo es, esencialmente, proteger la libertad y la dignidad de la persona. La segunda de esas tendencias se inclina a lograr una aplicación efectiva de la coerción penal. Su objetivo es lograr la mayor eficiencia posible en la aplicación de la fuerza estatal."

Sostiene: "la dialéctica eficiencia-garantía se resuelve en una síntesis culturalmente condicionada- de la que surgen los modelos procesales que conocemos actualmente y los que se han conformado a lo largo de la historia.,"

A ello se debe que los principios formativos a que aludimos sean ponderados y evaluados en el día a día a fin de obtener una suerte de equilibrio entre estas dos fuerzas que, evidentemente, se confrontan. Es decir, no queremos que se vulneren las garantías constitucionales, pero al propio tiempo queremos eficacia en la persecución penal, ¿ cómo obtenemos ese justo medio?

\footnotetext{
${ }^{17}$ BINDER. El Incumplimiento de las formas procesales, Buenos Aires. p. 56.

${ }^{18}$ Eficiencia y garantía en la formación del proceso penal, en Introducción al derecho procesal penal. Ad-Hoc $2^{\circ}$ ed. Buenos Aires, pag 56 y 57 .-
} 
La oralidad no es un valor en sí mismo, por cierto, sólo es la forma de asegurarnos la inmediación, pues sabemos que la escrituración, por concepto, la impide. Pero la otra virtud que tiene la oralidad es, a no dudarlo, la eficacia. En esta perspectiva podemos asegurar que es uno de los grandes aliados de la eficacia, como, por el contrario, la escrituración lo es de las garantías, en tanto mayor formalidad exigida, más seguridad entregada.

Pero se trata de buscar un justo medio. Es entonces cuando entran en juego, entre otros instrumentos, las autorizaciones judiciales previas: cuando el Código Procesal Penal contempla dentro del Libro I, "Disposiciones Generales, Título I, Principios Básicos" el artículo 9, que exige autorización judicial previa para toda actuación del procedimiento que privare, restringiere o perturbare al imputado o a un tercero del ejercicio de los derechos que la Constitución asegura, lo que pretende es establecer este justo medio.

Al analizar las diversas diligencias de investigación que pudieren producir estos efectos y que se encuentran expresamente reguladas en el código nos encontraremos con que hay cierta proporcionalidad entre la mayor o menor formalidad exigida en el proceso de autorización: presupuestos - requisitos para darla, materialización en un texto escrito para su exhibición al afectado, contenidos de mención obligatoria, y la mayor o menor intensidad intrusiva de la diligencia. Desde luego, las más intrusivas se someten a una regulación mayor. Podríamos decir que la gama de exigencias va desde una muy general y común a todas y que se refiere básicamente a la utilidad de la diligencia de investigación, ubicándose en este punto por ejemplo las del artículo 197 exámenes corporales, art. 206 pruebas caligráficas, art. 217 incautación de objetos y documentos, art. 226 fotografía u otros medios técnicos y respecto de las cuales la única "forma" exigida es precisamente la autorización, hasta una fuerte normativa respecto de la entrada y registro e interceptación, entre otras, en torno a las cuales aparte de la exigencia común de procedencia se ha creado todo un sistema de resguardo extremadamente detallado del ejercicio del derecho asegurado constitucionalmente y que será privado, restringido o perturbado.

Respecto de estas últimas, evidentemente no se pretende sostener que la autorización pueda ser expedida verbalmente, pues muchas veces se exige expresamente escrituración y en otros casos lo demanda su operatividad al hacerse alusión a ciertas menciones mínimas obligatorias y/o al deber de exhibirla o notificarla al afectado.

El análisis de las diversas normas del Código Procesal Penal referidas al tema, permite sostener que la escrituración de las autorizaciones no constituye una exigencia general. La regla, la garantía, la exigencia insoslayable es la autorización judicial previa en sí misma. Si se exige escrituración expresamente o lo demanda la operatividad de la 
actuación será necesario cumplir con ello, en cuyo caso estaremos frente a diligencias precisas y determinadas que, por su carácter intensamente intrusivo en la esfera de derechos cuyo ejercicio se encuentra asegurado constitucionalmente, son sometidas a un rígido marco de protección procesal de los mismos. Fuera de éstas, sin embargo, al analizar el resto de actuaciones de investigación de carácter menos instrusivo, advertimos que nada en su regulación, esencia ni mecanismos, permite afirmar que se necesita autorización escrita para su concreción, ni menos existe una norma de carácter general que imponga dicha obligación.

Ahora bien, sabemos que todas las actuaciones, policiales, fiscales y judiciales, deben registrarse. A ello se refieren los artículos 40 y siguientes del CPP en lo referente a las actuaciones judiciales y artículos 227 y siguientes del CPP en lo pertinente a los registros de la investigación, tanto fiscal como policial. En esta normativa sí encontramos en forma genérica la obligación de dejar constancia de las actuaciones tan pronto tuvieren lugar, consignándose una serie de datos mínimos a los que se alude. Por otro lado, en las normas que regulan específicamente ciertas diligencias, se reitera esta obligación haciendo incluso exigencias más detalladas y que tienen que ver con la naturaleza propia de la actuación. Esta obligación de registrar la actuación cuyo cumplimiento debe ser coetáneo o a lo más inmediatamente posterior a la realización de la misma tiene una finalidad muy clara: permitir revisar la legalidad de la actuación. Si por una parte tenemos un fiscal que necesita hacer una alcoholemia, y por otra a un imputado que se niega a ello, solicitará autorización para practicarla. Obtenida verbalmente dicha autorización, practicará la diligencia y registrará de inmediato este dato y otros que estime relevantes. Por su parte, el juez de garantía que dé la autorización procederá a dejar una constancia de la hora, día y circunstancias que motivaron su decisión, es decir, registrará su actuación. Con ello, lo que estamos asegurando es que el afectado pueda, con posterioridad a la práctica de la diligencia, plantear lo que estime pertinente a sus derechos. ¿Por qué con posterioridad? porque estamos en la hipótesis de una diligencia urgente, que de no ser ejecutada a la brevedad pierde su eficacia. El sistema cuenta con los mecanismos para reclamar las transgresiones adjudicando serias consecuencias procesales al responsable ( $\mathrm{v} . \mathrm{gr}$. exclusión de prueba) y, dando la posibilidad, eventualmente, de hacer efectivas las responsabilidades civiles, penales o administrativas en contra del transgresor.

Si analizamos el punto al revés, veremos que la posibilidad de que una autorización pueda darse verbalmente fuera del tribunal no está, por cierto, contemplada en norma alguna, pero ¿ es realmente necesario a ultranza que todo lo que debemos hacer los jueces esté así dicho?, es más, ¿sería ello posible?. Estimo que no sólo no es necesario, sino que tampoco es posible, porque claramente la realidad siempre supera la pretensión de anticiparse a través de una distante regulación normativa. La realidad es demasiado rica, innovadora en sí misma, creadora de mil y una situaciones que no es posible preveer. $Y$ es bueno que ni siquiera se intente, en 
tanto frente a la situación concreta es donde realmente se descubrirán sus posibilidades. No, no lo ha dicho una norma expresa, pero, a nuestro juicio lo dice la inteligencia del sistema, sus ideas fuerza, la lógica de sus principios.

La escrituración tuvo su época de oro. De hecho, junto al concepto de prueba legal tasada, doble instancia y otros fueron considerados grandes avances entregados a la humanidad por el sistema inquisitivo que el estado moderno trajo desde la justicia canónica a la justicia civil. Ciertamente, en el contexto de una europa analfabeta, entregar el enjuiciamiento popular a un grupo de funcionarios mejor preparados, si bien tuvo mucho que ver con la centralización del poder, también posibilitó la revisión por un superior jerárquico de la decisión necesariamente escrita tomada por un subalterno, lo que llevó ínsito un mejor control de los excesos y abusos en el ejercicio de este gran poder, como lo es el de administrar justicia.

Pero hoy día se ha pensado un sistema diverso. De acuerdo a la realidad actual del derecho, o mejor dicho, de la justicia con sus fortalezas y debilidades, podemos razonablemente sostener que los derechos del imputado están mucho más allá de la escrituración de las autorizaciones para practicar diligencias determinadas. EI imputado tiene verdaderamente asegurado sus derechos en la medida que cuente con un sistema sólidamente estructurado en torno a la presunción de inocencia que posibilite, en todas las etapas del procedimiento, un efectivo derecho a defensa.

Determinada la regla: verbalidad en la expedición de la autorizaciones, y la excepción: escrituración en aquellos casos que expresamente la ley lo exige o la operatividad de la diligencia lo demanda, es preciso tener presente que la ley 19.789 de 30 de enero de 2002, que introdujo modificaciones al Código Procesal Penal, vino sencillamente a poner en palabras en el artículo 9 del CPP lo que emanaba de su inteligencia: tratándose de casos urgentes, en que la inmediata autorización fuere indispensable para el éxito de la diligencia, podrá ser solicitada y otorgada por cualquier medio idóneo al efecto, tales como teléfono, fax, correo electrónico u otro, sin perjuicio de la constancia posterior.

\section{5.- Diferencia conceptual entre autorización judicial previa y orden judicial.}

El Código Procesal Penal usa inadvertidamente los términos "autorización" y "orden" judicial por lo que resulta necesario hacer claridad en torno a la diferencia conceptual entre ambos institutos.

Cuando hablamos de "autorizaciones" judiciales estamos en el ámbito de las diligencias de investigación que, por su naturaleza intrusiva, la nueva regulación ha exigido que pasen por un análisis jurisdiccional de pertinencia y procedencia antes de ser practicadas. La intervención judicial está pensada precisamente para resguardar el 
ejercicio de ciertos derechos constitucionalmente asegurados que se verán necesariamente amagados por la práctica de la diligencia que ha decidido realizar el fiscal. Claramente el juez no ha participado de la iniciativa en torno a la necesidad de la diligencia y los antecedentes que exigirá para tomar una decisión se ponderarán en la óptica del resguardo de los derechos individuales.

Una "orden" judicial tiene una naturaleza absolutamente diversa y encuentra su sustento más directo en el poder coercitivo propio de la labor jurisdiccional que en el artículo 34 del CPP sencillamente se ha explicitado.

No debe confundirse una diligencia autorizada por un juez de garantía con una actuación ordenada por el mismo. El fiscal tiene el total manejo de la primera por lo cual decidirá si la lleva en definitiva a cabo o no; en cambio, una actuación ordenada por el tribunal "debe" ser realizada y para ello el tribunal podrá ordenar directamente la intervención de la fuerza pública y disponer todas las medidas necesarias para su cumplimiento.-

Veamos un ejemplo: en una investigación por delito de tráfico de drogas en que el fiscal estima necesario llevar a cabo una diligencia consistente en la entrada y registro de un lugar cerrado. Solicita autorización previa al juez de garantía, quien, tras su análisis de procedencia y pertinencia, lo "autoriza". El fiscal, con esta autorización en sus manos "ordenará" a la policía que efectúe la actuación. Pero también puede suceder que el fiscal, en conocimiento de nuevos datos recientemente allegados estime que no es oportuno ejecutar esta diligencia y postergarla, o incluso desecharla definitivamente.-

\section{6.- Oportunidad para solicitar autorización judicial y juez competente para pronunciarse.}

La regla de la oportunidad la contiene el mismo artículo 9 del CPP al señalar en su inciso segundo que: "cuando una diligencia de investigación pudiere producir alguno de tales efectos, el fiscal deberá solicitar previamente autorización al juez de garantía". Los efectos a que se refiere están señalados en el inciso primero del mismo artículo: privar, restringir o perturbar al imputado o a un tercero del ejercicio de los derechos que la Constitución asegura.

Ahora bien, para solicitar esta autorización, según las reglas generales, el fiscal deberá formalizar la investigación. Esto nos lo indica el artículo 230 del CPP en los siguientes términos: "Cuando el fiscal debiere requerir la intervención judicial para la práctica de determinadas diligencias de investigación, está obligado a formalizar la investigación, a menos que lo hubiere realizado previamente. Exceptúanse los casos expresamente señalados en la ley." 
La excepción a que se refiere esta norma está contemplada en el artículo 236 del Código Procesal Penal en los siguientes términos: "Las diligencias de investigación que de conformidad al artículo $9^{\circ}$ requirieren de autorización judicial previa podrán ser solicitadas por el fiscal aun antes de la formalización de la investigación. Si el fiscal requiriere que ellas se llevaren a cabo sin previa comunicación al afectado, el juez autorizará que se proceda en la forma solicitada cuando la gravedad de los hechos o la naturaleza de la diligencia de que se tratare permitiere presumir que dicha circunstancia resulta indispensable para su éxito.

Si con posterioridad a la formalización de la investigación el fiscal solicitare proceder de la forma señalada en el inciso precedente, el juez lo autorizará cuando la reserva resultare estrictamente indispensable para la eficacia de la diligencia."

Como vemos, la conjugación de los artículos 230 y 236 puede dar lugar a diversas situaciones:

1.- Solicitud de autorización judicial previa para la práctica de una diligencia intrusiva con posterioridad a la formalización de la investigación.

2.-Solicitud de autorización judicial previa para la práctica de una diligencia intrusiva antes de la formalización de la investigación.

Y en ambos casos, antes o con posterioridad a la formalización de la investigación, puede solicitarse:

1. Con conocimiento del afectado.

2. Sin conocimiento del afectado.

Vale la pena detenerse un minuto en este punto, pues se han presentado algunos problemas.

Es posible que el fiscal solicite y el juez de garantía otorgue una autorización judicial para la práctica de una diligencia intrusiva antes de la formalización de la investigación y que ella se otorgue con conocimiento del afectado. Por ejemplo, puede el fiscal en una causa de abuso sexual a un menor, solicitar autorización para practicar un examen sicológico a un pariente de la víctima que se niega a ello por estimarlo denigrante, antes de la formalización y precisamente para contar con elementos serios que le permitan tomar la decisión de formalizar en contra de esa persona.

Asimismo, es también posible que el fiscal solicite y el juez de garantía otorgue una autorización judicial para la práctica de una diligencia intrusiva después de la formalización de la investigación, y que ella se otorgue sin conocimiento del afectado. 
Señala el inciso final del artículo 236 que el juez lo autorizará cuando la reserva resultare estrictamente indispensable para la eficacia de la diligencia.

Por último, si el fiscal solicita una autorización judicial para la práctica de una diligencia intrusiva antes de la formalización de la investigación y sin previa comunicación al afectado, señala el primer inciso del artículo 236 que el juez autorizará que se proceda en la forma solicitada cuando la gravedad de los hechos o la naturaleza de la diligencia de que se trata permita presumir que dicha circunstancia resulta indispensable para su éxito.

En lo referente al tema de la competencia para conocer esta solicitud y resolverla, dispone el artículo 70 inciso primero del CPP que el juez de garantía llamado por la ley a conocer las gestiones a que de lugar el respectivo procedimiento se pronunciará sobre las autorizaciones judiciales previas que solicite el ministerio público para realizar actuaciones intrusivas.

La regla del artículo 70 del CPP, en su inciso primero, se encuentra en armonía con las contempladas en los artículos $7^{\circ}$ y 157 del Código Orgánico de Tribunales.

El artículo $7^{\circ}$ del Código Orgánico de Tribunales señala: "Los tribunales sólo podrán ejercer su potestad en los negocios y dentro del territorio que la ley les hubiere respectivamente asignado.

Lo cual no impide que en los negocios de que conocen puedan dictar providencias que hayan de llevarse a efecto en otro territorio."

El artículo 157 del Código Orgánico de Tribunales (introducido por la ley 19.708, de 5 de enero de 2001) señala a su vez: "Será competente para conocer de un delito el tribunal en cuyo territorio se hubiere cometido el hecho que da motivo al juicio.

El juzgado de garantía del lugar de comisión del hecho investigado conocerá de las gestiones a que diere lugar el procedimiento previo al juicio oral.

El delito se considerará cometido en el lugar donde se hubiere dado comienzo a su ejecución.

Sin perjuicio de lo dispuesto en el inciso segundo, cuando las gestiones debieren efectuarse fuera del territorio jurisdiccional del juzgado de garantía y se tratare de diligencias urgentes, la autorización judicial previa podrá ser concedida por el juez de garantía del lugar donde deban realizarse. Asimismo, si se suscitare conflicto de competencia entre jueces de varios juzgados de garantía, cada uno de ellos estará facultado para otorgar las autorizaciones o realizar las actuaciones urgentes, mientras no se dirimiere la competencia." 
En otras palabras, el juez de garantía que tiene competencia en relación con el asunto y territorio, se pronunciará sobre las autorizaciones que solicite al fiscal para realizar diligencias intrusivas, sea que éstas se vayan a llevar a cabo dentro o fuera de su territorio.

Se precisa, sin embargo, que cuando se tratare de diligencias urgentes que debieren efectuarse fuera del territorio jurisdiccional del juzgado de garantía, el ministerio público también podrá pedir la autorización directamente al juez de garantía del lugar.

Esta es una novedad en tanto el fiscal pedirá directamente a un tribunal distinto del llamado por ley a conocer las gestiones a que dé lugar el respectivo procedimiento, la autorización que necesita, en razón de que la diligencia se ejecutará en su territorio, $\sin$ que medie solicitud (exhorto) del tribunal competente. En este caso, una vez realizada la diligencia, el ministerio público dará cuenta a la brevedad al juez de garantía del procedimiento.

\section{7.-Uso de la fuerza para llevar a cabo la diligencia autorizada judicialmente.}

Analizaremos un punto de trascendental importancia: una vez obtenida una autorización para una diligencia intrusiva ¿ puede el fiscal usar la fuerza para llevarla a cabo si ello fuere necesario?

Los ejemplos concretos siempre vienen en nuestra ayuda. Imaginemos que Carabineros fiscaliza a un conductor que conduce aparentemente en estado de ebriedad. Le señala que deberá practicarse la alcoholemia, el conductor se niega a practicá rsela voluntariamente ante lo cual el Fiscal solicita autorización judicial pues no olvidemos que la extracción de sangre es un examen corporal. El fiscal comunica al imputado que cuenta con una autorización judicial para proceder a la diligencia, sin embargo, éste mantiene tajantemente su negativa. Ante esto, reiteramos la pregunta: ¿ puede el fiscal usar la fuerza para proceder a la práctica de esta diligencia intrusiva?

A nuestro juicio sí puede hacerlo. Tendrá que, desde luego, usar su criterio para ponderar la relación costo-beneficio en la situación concreta. Tal vez estime que puede valerse de otros medios para acreditar el estado de ebriedad y prescindir de la alcoholemia, pero lo cierto es que tiene la facultad.

En un caso de poca trascendencia como el anotado tal vez no nos quede meridianamente clara la lógica de sistema que esta afirmación encierra, pero dediquemos un minuto a otro ejemplo: la policía encuentra a un niño muerto y violentado sexualmente a una cuadra de su casa. Del sitio de suceso se recoge y custodia celosamente vello púbico del presunto sospechoso, de quien no se tiene 
ninguna pista. Días más tarde una llamada anónima a la policía señala a un sujeto como el autor del crimen que se investiga, proporcionándose una serie de detalles que hace revestir este dato de gran seriedad. El fiscal cita al individuo y le pide que preste su consentimiento para extraerle sangre, a fin de practicar un examen de ADN. El sujeto se niega. El fiscal obtiene la autorización judicial y se lo comunica al sospechoso quien mantiene terminantemente su negativa. ¿Puede válidamente sostenerse que el fiscal no puede usar la fuerza para la práctica de esta diligencia? A nuestro juicio la respuesta es evidente y no es otra sino que el fiscal puede usar la fuerza racional y necesaria para llevar a cabo esta diligencia.

Si estamos pensando en una diligencia intrusiva respecto de la cual se solicitó autorización judicial previa, sabemos que el fiscal no contó con el consentimiento del sujeto para su realización y es esperable que, tras su otorgamiento, siga manifestando oposición. Es precisamente para actuar por sobre esa oposición que el fiscal obtuvo autorización judicial.

Lo que puede dar pie a un buen debate es si el examen corporal del que hablamos se ubica realmente en el segundo nivel de límites o si, por el contrario, se ubica más bien en el primer nivel, aquél que es intangible y que niega acceso al Estado para obtener la información.

Binder se refiere a este problema en los siguientes términos: "Se le pide (al imputado) que se efectúe un dosaje de alcohol. El problema reside, obviamente, en aquellos casos en los cuales el imputado no presta su consentimiento. Aquí hay dos soluciones posibles: o se asimila estos casos al primer nivel de protección y por lo tanto nos hallamos ante un límite infranqueable o se los asimila al segundo nivel de protección y, entonces, el límite puede ser superado con una autorización judicial. La solución no es fácil y no me atrevería a dar aquí una respuesta definitiva. No obstante, estimo que para estos casos parecería suficiente el segundo nivel de protección, con el consiguiente aumento de la rigurosidad- por su cercanía al primer nivel de protecciónya que, de lo contrario, el Estado se hallaría sin ninguna forma posible de suplir esta información y anularía la eficacia de otras pruebas, no directamente relacionadas con el imputado (v.gr. la eficacia de algunas pericias) ${ }^{19}$.

Sirva como dato, además, a tener presente a la hora de toma de posiciones, que en la discusión parlamentaria de esta nueva normativa, específicamente en el Senado, el invitado señor Giovanni Salvi, Magistrado Juez del Tribunal de Apelaciones y Fiscal Sustituto ante la Procuraduría de Roma expresó, refiriéndose a la intervención del juez de control durante la investigación que: "tal como está contemplada en el proyecto, no lleva el riesgo que el Presidente indicó", refiriéndose a la consulta efectuada por el

${ }^{19}$ BINDER. Justicia Penal y Estado de Derecho, Buenos Aieres, p. 29 y 30 
Presidente de la Comisión del Senado acerca de si estimaban que la injerencia otorgada al juez de control implicaba mantener rasgos del sistema inquisitivo. Fundando su respuesta agregó: "Porque, en este caso, el juez de control interviene cuando el Ministerio Público lo solicita sobre puntos muy específicos. En este sentido, no ejercita un verdadero control sobre la actividad de investigación del Ministerio Público, sino que garantiza los derechos del imputado respecto del ejercicio de los poderes coercitivos del Ministerio Público durante toda la investigación" ${ }^{20}$

Lo que puede presentarse dudoso en relación con una diligencia extremadamente intrusiva, como un examen corporal, no puede siquiera ser planteado respecto de otras diligencias que si bien necesitan autorización judicial previa no recaen directamente sobre la persona del imputado, como la entrada y registro en lugar cerrado, incautaciones, etc.

El fiscal ordena a la policía la práctica de estas diligencias en los mismos términos del artículo 11 del Código Orgánico de Tribunales, hoy modificado por la ley 19.665: "Para hacer ejecutar sus sentencias y para practicar o hacer practicar los actos de instrucción que decreten, podrán los tribunales requerir de las demás autoridades el auxilio de la fuerza pública que de ellas dependiere, o los otros medios de acción conducentes de que dispusieren.

La autoridad legalmente requerida debe prestar el auxilio, sin que le corresponda calificar el fundamento con que se le pide ni la justicia o legalidad de la sentencia o decreto que se trata de ejecutar."

Desde luego, el Ministerio Público cuenta con su propia normativa al efecto, de la que nos basta mencionar el artículo $80 \mathrm{~A}$ inciso tercero de la Constitución Política de la República, que señala: "El Ministerio Público podrá impartir órdenes directas a las Fuerzas de Orden y Seguridad durante la investigación," Y su parte final: "La autoridad requerida deberá cumplir sin más trá mite dichas órdenes y no podrá calificar su fundamento, oportunidad, justicia o legalidad, salvo requerir la exhibición de la autorización judicial previa, en su caso."

\footnotetext{
${ }^{20}$ Senado de la República Comisión de Constitución, legislación, justicia y Reglamento. Historia de la Ley Nuevo Código Procesal Penal (Boletin N 1630-07). Segundo Trámite Constitucional, p.64.
} 


\section{8.- Consecuencias derivadas de la realización de una diligencia intrusiva sin autorización judicial previa.}

Decíamos que la búsqueda de la verdad en el proceso reconoce como límite el respeto a los derechos de la persona humana, los que, al poder resultar afectados han obligado a los ordenamientos jurídicos a establecer ciertas formas de protección.

La manera de proteger los derechos individuales de la natural afectación que se produce por el ejercicio del poder punitivo del Estado es establecer ciertas formas, requisitos o secuencias, previas o coetáneas a la ejecución de determinadas diligencias o actuaciones, de modo tal que su omisión o quebrantamiento produzca la privación de sus efectos propios.

Las autorizaciones judiciales previas entran en esta lógica en primera línea. En efecto, éstas constituyen, a no dudarlo, un requisito insoslayable si lo que se pretende es realizar una diligencia investigativa que prive, perturbe o restrinja el ejercicio de un derecho constitucionalmente asegurado.

Con esto naturalmente no queremos decir que éste sea el único requisito, pues basta con examinar las normas que regulan las diligencias intrusivas en el Código Procesal Penal para darnos cuenta que existe toda una construcción protectora de los derechos que la Constitución asegura, dentro de la cual aparece como uno de sus pilares la expedición de estas autorizaciones.

Existen algunas construcciones más sólidas que otras, lo cual, hemos dicho va en directa proporción con la naturaleza más o menos intrusiva de la diligencia. Así, mientras más importante sea la penetración del círculo de mayor privacidad del imputado, encontraremos mayor protección, es decir, más exigencias de requisitos o cumplimiento de secuencias.

De esta manera podemos distinguir un primer cúmulo de requisitos que rodean la autorización judicial previa y luego, un segundo grupo que se preocupa de establecer otras exigencias formales que no dicen directa relación con la autorización misma, sino que rodean la ejecución material de la diligencia.

Los requisitos que rodean la autorización judicial previa van desde la expedición misma de la autorización, en la que ésta materializa la garantía, constituyendo un primer nivel en que el estándar de su procedencia está conformado por una mínima actuación tanto del fiscal como del juez y que se concretiza en la conversación que estos dos actores sostienen, uno solicitando la autorización y aportando mínimos antecedentes en torno al sujeto que soportará la práctica de la diligencia y ciertos datos acerca de la investigación en la que ésta se produce, y el otro acogiendo esta solicitud y 
por tanto expidiendo la autorización. Entre las diligencias de este tipo encontramos, por ejemplo, las pruebas caligráficas.

Avanzando en el nivel de requisitos encontramos aquellas diligencias que exigen ciertas condiciones previas para otorgar la autorización. En este caso se encuentran los exámenes corporales, tales como pruebas de carácter biológico, extracciones de sangre u otros análogos, que son permitidos en la medida que fueren necesarios para constatar circunstancias relevantes para la investigación y siempre que no fuere de temer menoscabo para la salud o dignidad del interesado.

Luego encontramos aquellas diligencias que, siendo aún más invasoras de la esfera de privacidad, suman condiciones más específicas, como la escrituración de la autorización y la inclusión de determinadas menciones.

De otra parte, podemos encontrar un segundo grupo de exigencias que no se relacionan con la autorización misma, sino con la forma de ejecución de la diligencia autorizada. Acá encontramos, por ejemplo, los horarios en que puede realizarse una entrada y registro de lugar cerrado, o que se trate de un hecho punible que merezca pena de crimen en las interceptaciones telefónicas.

En este acá pite debemos resolver acerca de las consecuencias que trae aparejada la ejecución de una diligencia sin autorización judicial previa, pero se han hecho las disquisiciones anteriores a fin de aclarar que existen diversas exigencias que se han establecido por el ordenamiento jurídico y que van más allá de la expedición de la autorización y que, en caso de transgresión pueden acarrear igualmente serias consecuencias para la persecución penal.

La respuesta a nuestra incógnita está dada por el artículo 276 del CPP: exclusión de pruebas para el juicio oral. El juez de garantía, luego de examinar las pruebas ofrecidas y escuchar a los intervinientes, ordenará fundadamente que se excluyan de ser rendidas en el juicio oral aquéllas que fueren manifiestamente impertinentes y las que tuvieren por objeto acreditar los hechos públicos y notorios.

Del mismo modo, agrega su inciso tercero, el juez excluirá las pruebas que provinieren de actuaciones o diligencias que hubieren sido declaradas nulas y aquéllas que hubieren sido obtenidas con inobservancia de garantías fundamentales.

Esto nos ubica en el tema de la ilicitud de la prueba obtenida y su consecuencia procesal: la exclusión de dicha prueba para el juicio oral.

Éste es un tema de proporciones gigantescas atendida su trascendencia y gran polémica en el ámbito jurídico internacional y que excede con mucho los objetivos de este acá pite, por lo cual nos limitaremos a señalar sus líneas más gruesas. 
Básicamente es ilícita la prueba que ha sido obtenida con violación de derechos fundamentales, consagrados en la Constitución Política de la República.

Es bueno para despejar este camino de conceptos nuevos, distinguir la prueba ilícita de otros conceptos afines como son prueba ilegal o irregular, prueba ilegítima, prueba viciada y prueba clandestina.

Es prueba irregular aquella obtenida o practicada con trangresión de normas que no participan de la construcción protectora de un derecho constitucional. "Dentro de este concepto podemos incluir las fuentes de prueba logradas de modo ilegal, así como los medios de prueba practicados irregularmente sin observar el procedimiento legal establecido, siempre que en ninguno de los dos supuestos se haya vulnerado un derecho fundamental". ${ }^{21}$

Picó Junoy da como ejemplo de prueba ilegal las fuentes de prueba logradas mediante hurto o robo, "en la medida que el derecho de propiedad no ha sido configurado por nuestra Carta Magna como fundamental". Agrega que "ello no obsta para que, en el supuesto de haberse infringido con dicha acción algún derecho fundamental (el referente a la intimidad de las personas del art. 18.1 C.E., o a la inviolabilidad del domicilio del art. 18." C.E., entre otros), dicha fuente probatoria deba ser admitida en el proceso." ${ }^{22}$ Naturalmente este ejemplo es válido para la legislación española, pero no lo es para nuestro país que sí brinda protección constitucional al derecho de propiedad.

Al propio tiempo indica, a modo de ejemplo de una prueba irregular "la declaración del testigo que no se le han formulado las preguntas que el artículo 648 L.E.C. ordena realizarle; la falta del necesario juramento del cargo de perito, tal y como prescribe el art. 618 L.E.C para la validez del informe pericial; o la inexistencia del juramento de decir verdad previsto en el art. 634. II L.E.C. para la declaración de la persona práctica en el terreno en la prueba de reconocimiento judicial." ${ }^{23}$

El concepto de prueba ilegítima se encuentra en la doctrina italiana, distinguiéndose de la ilícita, según la infracción se cometa respecto de una norma material o procesal.

La prueba viciada de que hablan algunos autores, se refiere a la capacidad de ser valorada como veraz, con total independencia de su modo de obtención.

\footnotetext{
${ }^{21}$ PICÓ JUNOY. El derecho a la prueba en el proceso civil. p. 291

${ }^{22}$ Senado de la República Comisión de Constitución, legislación, justicia y Reglamento, Historia de la Ley Nuevo Código Procesal Penal (Boletín N 1630-07). Segundo Trámite Constitucional, p. 290.

${ }^{23}$ Senado de la República Comisión de Constitución, legislación, justicia y Reglamento, Historia de la Ley Nuevo Código Procesal Penal (Boletín N 1630-07). Segundo Trámite Constitucional, p. 291.
} 
La prueba clandestina, por último, es aquélla que se obtiene con un comportamiento oculto, infringiendo la intimidad o privacidad de las personas. Este concepto no aporta ninguna particularidad en tanto se encuadra perfectamente dentro del de prueba ilícita.

Nuestro Código Procesal Penal no bautizó con nombre alguno a la prueba "obtenida con inobservancia de garantías fundamentales", pero claramente es aquélla que la doctrina denomina "prueba ilícita". Nuestro Código es claro en señalar la consecuencia que trae el tratar de incorporar al juicio una prueba de esta naturaleza: será excluida por el juez de garantía en la audiencia de preparación del juicio oral.

Una prueba obtenida en una diligencia intrusiva realizada sin consentimiento del imputado y sin autorización judicial previa será excluida por el juez. Aparece aquí claramente manifestado el carácter de "garantía" que reviste esta exigencia, al privar de efectos al acto afectador del derecho cuyo ejercicio la Constitución se ha preocupado de asegurar.

La inadmisibilidad de la prueba ilícita en nuestro sistema está instituida en términos imperativos. Los grandes debates que se produjeron y se producen aún en las realidades jurídicas comparadas en torno al punto fueron zanjadas de fondo por nuestra nueva normativa, sin embargo es bueno tener presente al menos un par de argumentos que sostienen las dos posiciones que tradicionalmente se han enfrentado en este tema.

A favor de la admisión y eficacia de las pruebas obtenidas se esgrimen principalmente los siguientes argumentos, sintetizados por Joan Picó Junoy ${ }^{24}$, refiriéndose a la admisibilidad de la prueba irregular o ilegal, por haber perdido interés en España la discusión en relación con la prueba ilícita tras la dictación de la Ley Orgánica del Poder Judicial de 1985, en cuyo artículo 11.1 se proscribe la eficacia de las pruebas logradas con infracción de derechos fundamentales:

1.- El principio de la búsqueda de la "verdad procesal" y la justicia como fin de todo proceso. En la confrontación de intereses que se entrecruzan en esta problemática, a saber, el interés colectivo en esclarecer los hechos tal y como realmente ocurrieron a objeto de asegurar el orden jurídico, y el interés igualmente colectivo de la protección de los derechos individuales legalmente establecidos, dicha doctrina opta por el primero de ellos, pues el segundo se garantiza y preserva mediante la sanción civil o penal a quien haya obrado antijurídicamente.

\footnotetext{
${ }^{24}$ PICÓ JUNOY. El derecho a la prueba en el proceso civil. p. 283 y ss.
} 
2.- El principio de autonomía de las normas procesales respecto de las materiales. ${ }^{25}$ Representante de esta posición es el jurista italiano Cordero, quien expresa que la prueba encarada como fenómeno judicial encuentra su disciplina en lo interno del proceso: por tanto, si un aporte probatorio reconoce su origen en un ilícito sustancial, desde el punto de vista procesal no existirá reacción del ordenamiento jurídico contra la conducta violatoria del derecho, $\operatorname{sino}_{26}$ en la medida que exista una prohibición procesal probatoria más o menos explícita.

3.- El carácter metajurídico de la prueba. La prueba en sí misma considerada tiene un carácter marcadamente metajurídico, como actividad de reconstrucción o descubrimiento de unos hechos que tiene por objeto trasladarlos a presencia judicial, por lo que sus resultados no deben medirse en términos de moralidad, sino de verosimilitud.

Joan Picó Junoy cita a pie de página un ejemplo dado por Muñoz Sabaté quien destaca que "el carácter expoliativo de las innumerables obras de arte egipcio guardadas en los museos de Londres y París no altera para nada las conclusiones históricas que de ellas obtuvieran un Schliemann, un Champollion o un Howard Carter".

4.-El argumento de la no doble sanción por un mismo acto. Mediante este argumento, la doctrina destaca la indebida acumulación de "sanciones" que supondría la inadmisibilidad de la prueba ilícita y la responsabilidad que la misma puede originar. La eficacia de tales pruebas no supone una complacencia con las mismas, por lo que la mayoría de los autores que admiten dicha eficacia destacan que el infractor de la legalidad debe someterse a la correspondiente responsabilidad civil, administrativa o penal derivada de su actuación.

5.- El principio "factum infectum fieri nequit" Este principio, que puede expresarse en la idea de que lo hecho no puede devenir no hecho, es utilizado por algún autor para otorgar validez y eficacia a la prueba aquí analizada, concretamente los actos, declaraciones y comportamientos que las partes eventualmente han podido realizar en el proceso respecto de esta prueba.

Se formulan, de contrario, los siguientes argumentos a favor de la inadmisibilidad de esta prueba, sintetizados por el mismo autor:

\footnotetext{
${ }^{25}$ Senado de la República Comisión de Constitución, legislación, justicia y Reglamento, Historia de la Ley Nuevo Código Procesal Penal (Boletín N 1630-07). Segundo Trámite Constitucional, p. 291.

${ }^{26}$ MINVIELLE. Opúsculos de Derecho Penal y Criminología. La prueba ilicita en el Derecho Procesal Penal, p. 23 y 24.
} 
1.- La concepción del proceso como instrumento de resolución jurisdiccional de litigios dentro del respeto al ordenamiento jurídico. Si el proceso se concibe como el medio para resolver jurisdiccionalmente los conflictos intersubjetivos, disciplinado jurídicamente por un conjunto de normas y principios, ello conduce a sostener que todo acto que infrinja dicho sistema debe ser excluido del mismo.

2.- El principio general del derecho "nemo ex delicto conditionem suam meliorem facere potest". Este principio viene a significar que los actos ilícitos no pueden aprovechar o beneficiar al autor de los mismos. Para algunos autores es plenamente aplicable a la prueba ilegalmente obtenida.

3.- Su efecto disuasorio, garantizador de la eficacia de la norma vulnerada. Sancionando a la prueba ilegalmente obtenida con la inadmisión procesal, se alcanzan dos trascendentales objetivos: el primero, disuadir a potenciales infractores del orden jurídico de su estéril actuar. En esta línea se afirma que la única respuesta que el ordenamiento jurídico debe dar a su violación no es otra que el rechazo absoluto de lo obtenido con dicha actuación, pues sólo así puede desalentarse a quienes pretendan recurrir a tales artimañas. Cita este autor al juez Holmes, Presidente del Tribunal Supremo de los Estados Unidos entre 1902 y 1932, quien afirmaba que "si éstos conocen la ineficacia procesal de su actuar, sin duda desistirán de efectuar actuaciones al margen de la ley. Ciertamente, este postulado puede llevar en ocasiones a dejar impunes conductas delictivas pero, a su juicio, es preferible que algunos delincuentes escapen a la acción de la justicia, antes que el gobierno desempeñe un papel indigno."

El segundo objetivo que pretende alcanzarse con la inadmisión de las pruebas ilegales es proteger la norma vulnerada, negando toda virtualidad o eficacia jurídica a lo logrado con su infracción. Lo opuesto -destacan algunos autores- supone legitimar o convalidar judicialmente tales actos contrarios a derecho.

4.- La nulidad del acto material de obtención del elemento probatorio comporta la nulidad posterior de toda su eventual eficacia (quod nullum est, nullum producit effectum). Con base en la unidad del ordenamiento jurídico se argumenta que toda violación de una norma que lo integra, sea material o procesal, afecta a éste en su conjunto y sin distinción alguna.

Subsiste otra discusión de gran envergadura que es de diversa solución en el derecho comparado y que sí será objeto de análisis en el nuevo proceso penal. Es el referente a la admisibilidad de la prueba derivada.

El problema consiste en decidir si se admite una prueba derivada de la ilícita, que es denominada por la doctrina americana "fruit of the poisonous tree": frutos del árbol envenenado. 
Supongamos que se realiza una entrada y registro en lugar cerrado sin cumplir con las formalidades que rodean esta diligencia, por ejemplo sin haber obtenido autorización judicial previa. No tenemos duda que los objetos hallados en este registro serán excluidos por ilicitud, al haber sido obtenidos con inobservancia de garantías fundamentales. Sin embargo, cabe la pregunta acerca de la admisibilidad de las declaraciones de los testigos, cuyos datos fueron ubicados a partir de la información que contenía una agenda que se encontró en el inmueble.

Como decíamos las soluciones frente a este problema son diversas, destacándose en la línea de la inadmisibilidad de la prueba, la mencionada doctrina de los frutos del árbol envenenado.

Esta doctrina tiene su origen en la jurisprudencia norteamericana en el caso "Silverthorne Lumber Co. V/S. United States, 1929", en el que se decidió no admitir la prueba obtenida en procedimientos policiales ilícitos, debido a que ello contravenía preceptos constitucionales establecidos en la IV Enmienda.

La expresión que alude a esta doctrina la acuño el Juez Franfurter en el caso "Nardone v/s. United States, 1939" en los siguientes términos: "Once that is established-as was plainly done here-the trial judge must give opportunity, however closely confined, to the accused to prove that a substantial portion of the case against him was a fruit of the poisonous tree. This leaves ample opportunity to the Government to convince the trial court that its proof had an independent origin".

Esta doctrina ha sufrido una evolución que tiende a su debilitación progresiva, manifestada en los límites que se ha fijado a su vigor en los diversos casos que se han presentado, sobre la base de criterios como el de la buena fe del agente (good faith), o del descubrimiento inevitable (inevitable discovery).

El criterio de la buena fe del agente básicamente consiste en admitir la prueba obtenida en procedimientos policiales ilícitos y la derivada de la misma, si en ellos la policía ha actuado "in good faith."

Por su parte, en el criterio del descubrimiento inevitable se admite la prueba obtenida en procedimientos ilícitos si la misma hubiere sido inevitablemente descubierta por otros medios legales.

Ésta será una discusión posible en el marco del nuevo proceso, en tanto no hay solución normativa expresa al respecto.

Una posición posible será que al existir sólo referencia en el artículo 276 del CPP a la exclusión de "la prueba obtenida con inobservancia de garantías fundamentales" la inadmisibilidad sólo estaría establecida en relación con la prueba obtenida directamente 
del procedimiento ilícito y que, por el contrario, aquella devenida indirectamente es perfectamente admisible.

Por otro lado, se puede argumentar que esta generalidad precisamente es la que no sólo permite, sino que obliga, a excluir toda prueba obtenida con inobservancia de garantías fundamentales, incluyéndose por tanto aquella obtenida directa o indirectamente del procedimiento realizado con la cuestionada inobservancia.

La última palabra la tendrán los actores del nuevo proceso, principalmente los jueces de garantía, custodios de las garantías de todos los intervinientes. 